\title{
Dos habitus de classe aos patrimônios individuais de disposições: reflexões sobre a prática em Pierre Bourdieu e Bernard Lahire
}

ANA RODRIGUES GAUALCANTI ALUES*

\section{Resumo}

O presente trabalho visa analisar as contribuições teóricas de Pierre Bourdieu e Bernard Lahire na construção de uma sociologia da prática, destacando o esforço dos autores em superar as dicotomias que dividem as principais correntes sociológicas - entre objetivismo e subjetivismo, indivíduo e sociedade. Para tanto, serão apresentados os caminhos traçados pelos autores para pensar a agência humana, através de uma teoria disposicional da ação, que enfatiza os habitus de classe ou as disposições individuais. Por fim, discutiremos os avanços e limites observados nessas perspectivas na apreensão de questões centrais da teoria social contemporânea, como a capacidade reflexiva dos atores e seu papel na reprodução/ transformação do mundo social. Essa análise permite questionar em que medida os autores conseguem superar as referidas dicotomias, uma vez que terminam por enfatizar o peso do social sobre as condutas individuais.

Palavras-chave: Prática. Habitus de classe. Disposições individuais. Pierre Bourdieu. Bernard Lahire.

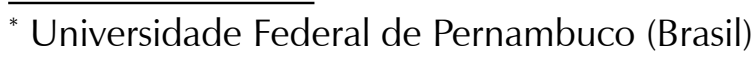




\title{
From habitus of class to individual heritage of dispositions: reflections on the practice in Pierre Bourdieu and Bernard Lahire
}

\begin{abstract}
The present work analyzes the theoretical contributions of Pierre Bourdieu and Bernard Lahire in the construction of a sociology of practice, highlighting their efforts to overcome the dichotomies that divide the main sociological theories - between objectivism and subjectivism, individual and society. In this sense, I will present the paths traced by them to think about human agency through a dispositional theory of action, emphasizing class habitus or individual dispositions. Last but not least, I discuss the progress and limits observed in these perspectives in grasping the central issues of contemporary social theory, such as the reflexive capacity of actors and their role in the reproduction /transformation of the social world. This analysis allows us to question to what extent the authors can overcome these dichotomies, because they emphasize, ultimately, the weight of the social on the individual conduct.
\end{abstract}

Keywords: Practice. Class Habitus. Individual dispositions. Pierre Bourdieu. Bernard Lahire. 


\section{Introdução ${ }^{1}$}

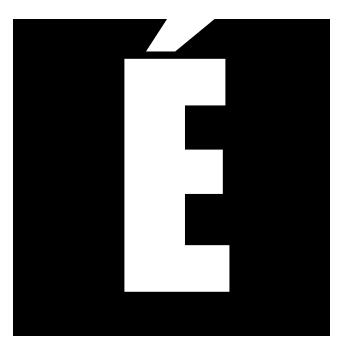

possível afirmar que o surgimento da sociologia é concomitante ao nascimento do indivíduo na modernidade, marcada por uma transformação fundamental na relação entre indivíduo e sociedade e por um maior espaço conferido a ele nas relações sociais. Assim, embora a consolidação da sociologia como disciplina autônoma tenha sido marcada por um esforço em desvendar as determinações sociais na explicação da vida social, sempre houve um interesse, por parte de seus meIhores teóricos, pela análise das dimensões individuais (Martucelli, 2007). A história da sociologia sempre esteve marcada por um debate acerca das dicotomias entre indivíduo e sociedade, subjetivismo e objetivismo e, mais recentemente, entre agência e estrutura, em torno das quais se desenvolveram as principais correntes sociológicas, atribuindo maior ênfase a uma ou a outra dessas esferas na explicação da ordem social.

Pierre Bourdieu se destaca nesse debate por tentar superar tais dicotomias, desenvolvendo uma teoria da prática que busca integrar as contribuições teóricas legadas por ambos os enfoques; teoria cujo cerne consiste na relação dialética entre condutas individuais propelidas por disposições socialmente adquiridas do habitus, de um lado, e estruturas objetivas ou "campos" de relações entre agentes diferencialmente posicionados, de outro. No entanto, muitos críticos afirmam que sua abordagem praxiológica não consegue superar de maneira satisfatória essas dicotomias, uma vez que ele confere uma precedência teórica às relações

\footnotetext{
${ }^{1}$ Agradeço o incentivo e colaboração da professora Cynthia Hamlin pela leitura e revisão crítica deste artigo, assim como aos pareceristas anônimos da Revista Sociologias, pelas contribuições no amadurecimento de muitas ideias aqui contidas.
} 
objetivas, negligenciando dimensões importantes das condutas individuais (Peters, 2013, p. 47).

Já Bernard Lahire se aproxima de uma perspectiva sociológica, desenvolvida nas últimas décadas, que defende a necessidade de uma nova abordagem teórica à escala individual, haja vista o crescente processo de diferenciação na sociedade moderna, intensificado a partir da segunda metade do século XX. Diante desse processo, o indivíduo passa a circular por uma pluralidade de esferas sociais na modernidade, de modo que se faz necessário prestar mais atenção no trabalho que ele realiza sobre si mesmo. Nessa perspectiva, o autor parte de um diálogo crítico com a teoria da prática de Bourdieu, buscando construir uma teoria disposicional do indivíduo.

Enquanto Bourdieu enfatizou certa homogeneidade entre os agentes produzida pelos habitus comuns de classe, tendo evocado apenas tardiamente os habitus individuais, Lahire acentua os processos multiformes de incorporação do social e privilegia a tensão entre as diversas disposições interiorizadas pelo indivíduo. Mas apesar de seu esforço em apreender as variações interindividuais e intraindividuais da prática, bem como a importância dos hábitos reflexivos, o autor permanece dentro de uma perspectiva que enfatiza o peso dos processos socializadores na moldagem da subjetividade individual.

Neste trabalho, será desenvolvida uma discussão comparativa acerca das contribuições teóricas de Bourdieu e Lahire na construção de uma sociologia da prática, destacando os caminhos apontados pelos autores para pensar sociologicamente a agência humana, a partir de uma teoria disposicional da ação. Nessa discussão, faz-se necessário enfatizar as semelhanças e diferenças entre os dois enfoques, bem como seus avanços e limites na apreensão de questões centrais da teoria social contemporânea, como a capacidade reflexiva dos atores e seu papel na reprodução/ transformação do mundo social. 


\section{Pierre Bourdieu: os habitus de classe}

Bourdieu desenvolve sua teoria da prática numa tentativa de superar a oposição artificial entre duas perspectivas aparentemente inconciliáveis que dividem as ciências sociais. De um lado, a perspectiva objetivista, que procura explicar a vida social não pela concepção dos seus participantes, mas pelas causas profundas que escapam à consciência. De outro lado, a posição subjetivista, que concebe o mundo social a partir das representações que dele fazem os agentes e atribui à ciência social a tarefa de construir uma "interpretação das interpretações" produzidas pelos sujeitos sociais. Trata-se, portanto, de duas concepções completamente opostas da ciência:

no primeiro caso, o conhecimento científico só é obtido mediante uma ruptura com as representações primeiras - chamadas 'prenoções' em Durkheim e 'ideologia' em Marx que conduz às causas inconscientes. No outro caso, ele está em continuidade com o conhecimento de senso comum, já que não passa de uma "construção das construções" (Bourdieu, 1990, p. 151).

Analisando o contexto histórico e intelectual de formação do pensamento de Bourdieu, Gabriel Peters (2013, p. 48) afirma que a oposição entre a "física social" e a "fenomenologia social" que o autor tenta superar teve como referência primeira o embate teórico, presente no campo intelectual francês após a Segunda Guerra Mundial, entre o existencialismo de Sartre e o estruturalismo. Sob a influência do estruturalismo, Bourdieu (2013a, p. 70) critica a concepção do sujeito sartreano - individual ou coletivo - cujas ações dependem inteiramente da consciência e se fundamentam na livre resolução do juramento e da fidelidade a si mesmo, não sendo influenciadas pelo passado ou pelo porvir².

\footnotetext{
${ }^{2} \mathrm{O}$ autor reconhece em Sartre o mérito de ter dado uma formulação ultraconsequente à filosofia da ação que descreve as práticas como estratégias explicitamente orientadas com referência a fins, explicitamente estabelecidos por um projeto livre.
} 
A crítica de Bourdieu reflete o declínio da fenomenologia existencialista de Sartre e a ascensão do estruturalismo como paradigma multidisciplinar nos anos 1960. Para Bourdieu (Ibid., p. 152), a maior contribuição da revolução estruturalista - considerada como um dos modos de conhecimento objetivista - consistiu em aplicar ao mundo social um modo de pensamento relacional, que identifica o real não a substâncias, mas a relações. A "realidade social" é concebida como um conjunto de relações invisíveis, que constitui um espaço de posições exteriores umas às outras, definidas umas em relação às outras. $\mathrm{O}$ autor afirma que a sociologia, em seu momento objetivista, deve consistir numa análise das posições relativas e das relações objetivas entre essas posições.

No entanto, Bourdieu (1990) defende que, após uma ruptura epistemológica com as representações primeiras, é preciso realizar uma segunda ruptura com o próprio objetivismo. Do mesmo modo que o subjetivismo tende a reduzir as estruturas às interações, o objetivismo tende a deduzir as ações e interações das estruturas, conduzindo a um realismo da estrutura, que hipostasia as relações objetivas, tratando-as como realidades já constituídas fora do indivíduo e do grupo. A sociologia deve incluir também um estudo da percepção do mundo social, pois as percepções e representações também contribuem para a construção desse mundo, sendo fundamentais para explicar as lutas cotidianas que visam transformar ou conservar as estruturas sociais.

Faz-se necessário introduzir na construção do conhecimento sociológico a ideia defendida pelas chamadas microssociologias, sobretudo pela Etnometodologia de Garfinkel (2009), de que o mundo social é uma realização de seus membros, recuperando o peso causal das dimensões subjetivas na reprodução desse mundo, que só é possível através das práticas dos indivíduos. Contudo, Bourdieu (2012, p. 44) critica os etnometodólogos por se limitarem à descrição dessa experiência, sem questionar 
as condições sociais que a tornam possível, ou seja, a adequação entre as estruturas objetivas do mundo e as estruturas cognitivas que possibilitam a sua apreensão.

O autor adverte que tais percepções são sempre tomadas a partir de uma determinada posição no espaço social. Os agentes têm uma apreensão ativa do mundo e constroem sua visão de mundo, mas o que se perde numa análise que busca as formas invariantes da percepção da realidade social é que esta construção não é operada num vazio social, mas está submetida a coações estruturais. A análise sociológica das dimensões subjetivas torna-se fundamental justamente pelo seu "caráter objetivo", dado que as formas simbólicas possuem uma lógica e eficácia própria, que lhe garante uma autonomia relativa com relação às condições objetivas apreendidas nas distribuições.

É o caráter intrinsecamente duplo da realidade, que inclui tanto propriedades materiais quanto propriedades simbólicas - e essas nada mais são do que as propriedades materiais quando percebidas como propriedades distintivas -, que implica a necessidade de superação da oposição entre subjetivismo e objetivismo na ciência social. Para tanto, faz-se necessário, segundo Bourdieu (2013a, p. 87), situar-se no princípio da relação dialética entre as condições objetivas e as disposições estruturantes, geradas pelos esquemas classificatórios do habitus, ou seja, é preciso retornar à prática, como lugar da dialética entre os habitus e as estruturas.

O autor desenvolve sua teoria da prática através da introdução de uma relação suplementar: um relacionamento vertical que estabelece a mediação entre o sistema de posições objetivas e as disposições subjetivas (Vandenberghe, 2010, p. 64). Trata-se do conceito de habitus, que foi retomado por Bourdieu para forjar uma teoria disposicional da ação, capaz de reintroduzir na perspectiva estruturalista a capacidade inventiva dos agentes, sem retroceder ao intelectualismo cartesiano que enviesa as abordagens subjetivistas da conduta social (Wacquant, 2007, p. 64). 
Tal conceito está na raiz da concepção bourdieusiana de agência humana, uma vez que enfatiza a constituição histórica e social dos indivíduos, mas também o papel fundamental destes na própria constituição da sociedade. Como mostra Peters (2010, p. 9), o pensamento de Bourdieu se insere numa perspectiva teórico-metodológica que considera as estruturas de personalidade dos agentes individuais como sendo moldadas substancialmente pela sua trajetória experiencial no interior de contextos socio-históricos específicos. Nesse sentido, a subjetividade dos atores individuais seria moldada pelas marcas estruturais e processos socializadores no interior dos quais se desenvolve sua biografia, de modo a abranger tanto os seus aspectos motivacionais - seus desejos e impulsos explícitos ou inconscientes - quanto seus aspectos recursivos - suas habilidades cognitivas, expressivas e práticas, necessárias à intervenção no mundo societário. $\mathrm{O}$ autor destaca os aspectos recursivos da subjetividade, na medida em que eles permitem perceber que a estruturação socializadora da personalidade, na teoria de Bourdieu, não possui apenas um caráter restritivo, mas também uma dimensão habilitadora que fornece aos indivíduos uma gama de recursos, tornando-os aptos para contribuir na reprodução/transformação do mundo social. A partir dessa dimensão, ficaria evidenciado o caráter dialético da relação entre indivíduo e sociedade, ancorada no habitus, que está na base não apenas da sociação, mas também da individuação dos agentes.

Partindo dessa perspectiva, Bourdieu (2013a, p. 87) define os habitus como

sistemas de disposições duráveis e transponíveis, estruturas estruturadas predispostas a funcionar como estruturas estruturantes, ou seja, como princípios geradores e organizadores de práticas e de representações que podem ser objetivamente adaptadas ao seu objetivo sem supor a intenção consciente de fins e o domínio expresso das operações necessárias para alcançá-los, objetivamente 'reguladas" e 
'regulares' sem em nada ser o produto da obediência a alguma regra e, sendo tudo isso, coletivamente orquestradas sem ser o produto da ação organizadora de um maestro.

Com essa definição, o autor busca responder a uma leitura economicista da teoria da ação, que só reconhece a ação racional orientada por interesses econômicos, tratados como fins conscientemente estabelecidos ou como reações mecânicas, impostas por determinações de mecanismos exteriores e superiores aos agentes. Essa leitura impede justamente a compreensão da lógica de todas as ações que são razoáveis sem ser o produto de um plano razoável, coerentes sem serem originárias de uma intenção de coerência, ajustadas ao futuro sem ser o resultado de um projeto ou de um plano.

A coerência observada no conjunto das práticas e propriedades de um agente ou de um conjunto de agentes - que são o produto de condições semelhantes- seria resultante da aplicação de esquemas idênticos ou mutuamente convertíveis, que possibilitam um ajuste das disposições subjetivas às condições objetivas. O habitus se constitui em necessidade incorporada (necessidade tornada virtude) que, por ser o produto de uma classe determinada de regularidades objetivas, tende a engendrar todas as condutas razoáveis. E essas condutas têm toda possibilidade de serem sancionadas positivamente, haja vista que são objetivamente ajustadas à lógica característica de um campo determinado.

Do mesmo modo, as antecipações do habitus constituem uma espécie de hipóteses práticas, que se fundamentam nas experiências passadas. Bourdieu (Ibid., p. 89) atribui um peso causal importante às experiências primeiras nas quais se produzem as estruturas do habitus, que estão no princípio da percepção e apreciação de toda experiência ulterior. Desse modo, as práticas dos agentes nunca estão submetidas apenas às pressões imediatas da conjuntura. Não é possível deduzi-las nem das condições pre- 
sentes que parecem tê-las suscitado, nem das condições passadas, nas quais o habitus foi produzido, uma vez que essas práticas tendem a reproduzir as condições nas quais foi criado seu princípio gerador e, ao mesmo tempo, a ajustar-se às exigências inscritas como potencialidade na situação. A ação é concebida como produto da relação dialética entre habitus e situação.

A incorporação de disposições subjetivas ocorre através de um processo de aprendizagem pelo qual o indivíduo passa ao longo de sua trajetória e de suas experiências particulares, de maneira durável e sistemática, mas não mecânica, nem irreversível. Na Distinção, Bourdieu (2013b) demonstra como alguns indivíduos adquirem competências culturais e estabelecem uma relação específica com a cultura através de um aprendizado profundo, precoce e insensível, que tem início desde a mais tenra idade, no seio da família, e que é prolongado posteriormente pela socialização escolar. Contudo, esse não é o único modo possível de aquisição da cultura, de modo que alguns indivíduos passam por um processo de aprendizagem tardio, metódico e acelerado, sobretudo quando são desprovidos de uma socialização familiar que propicie a aquisição precoce de competências culturais.

Portanto, a incorporação de disposições está diretamente ligada às condições objetivas do indivíduo e à posição que ele ocupa no sistema de relações sociais. Buscando escapar de certo determinismo de classe, o autor enfatiza que as condições objetivas delimitam as práticas, adaptando-as às necessidades das quais resulta seu princípio gerador, mas não as determinam totalmente ${ }^{3}$. Assim, as condições semelhantes podem gerar habitus

\footnotetext{
${ }^{3}$ É importante destacar que Bourdieu (2013a, 2013b) rejeita as concepções substancialistas da classe social em favor de uma concepção relacional, que define a classe pela posição ocupada no espaço social, ou seja, na distribuição de recursos que são ou podem se tornar operantes, tais como o capital econômico, cultural e social. Essa perspectiva relacional é fundamental para superar a oposição entre objetivismo e subjetivismo, que tem na teoria das classes sociais um de seus principais terrenos.
} 
substituíveis que engendram práticas diversas e imprevisíveis em seu detaIhe singular, segundo a lógica específica de cada habitus individual.

Embora reconheça que os membros de uma mesma classe não passam pelas mesmas experiências numa mesma ordem, o autor afirma que os agentes oriundos de uma mesma classe têm muito mais possibilidade de ter se deparado com situações semelhantes do que qualquer outro membro de outra classe. Assim, a sociologia pode tratar como idênticos os indivíduos biológicos que, sendo o produto das mesmas condições objetivas, são dotados dos mesmos habitus, como sistemas de disposições comuns a todos aqueles que são o produto de condicionamentos sociais idênticos ou semelhantes. Ao apreender as estruturas objetivas, sob a forma de probabilidade de acesso aos bens, aos serviços e aos poderes, a ciência pode alcançar o sentido de realidade que tais estruturas inculcam nos agentes, através de experiências sempre convergentes que atribuem sua fisionomia ao entorno social, com suas carreiras fechadas, seus lugares inacessíveis e seus horizontes obstruídos.

Assim, apesar de reconhecer as diferenças irredutíveis entre os habitus dos indivíduos particulares e a existência de uma individualidade orgânica dada à percepção imediata e socialmente designada (nome próprio, pessoa jurídica etc.), Bourdieu (2013a, p. 99) define o habitus de classe como o habitus individual na medida em que exprime ou reflete a classe como um sistema subjetivo, mas não individual, de estruturas interiorizadas; esquemas comuns de percepção, pensamento e ação. São esses esquemas comuns que permitem fundar toda concertação objetiva das práticas e a unicidade da visão do mundo na impessoalidade e na substituibilidade perfeitas das práticas e das visões singulares.

Trata-se de uma relação de homologia; de diversidade na homogeneidade, que une os habitus singulares dos diferentes membros de uma mesma classe e que reflete a própria diversidade na homogeneidade 
característica de suas condições sociais de produção. Cada sistema de disposições individual é considerado como uma variante estrutural dos outros, que exprime a singularidade da posição no interior da classe e da trajetória. Se, por um lado, o autor enfatiza a existência de um estilo comum entre os membros de uma mesma classe, ele também destaca, por outro lado, a presença de diferenças significativas entre os habitus individuais que remetem à singularidade das trajetórias sociais, uma vez que cada habitus realiza uma integração única entre as experiências passadas e presentes.

A teoria de Bourdieu tem sido criticada pela sua ênfase excessiva no ajuste proporcionado pelo habitus entre condições objetivas e disposições subjetivas, conduzindo a uma relação circular de reprodução quase perfeita. Mas é importante destacar que, para o autor, tal relação de ajustamento antecipado do habitus só é possível quando ele encontra condições favoráveis à sua atualização, ou seja, quando as condições objetivas nas quais ele foi gerado são semelhantes às de seu funcionamento no presente. E tal ajustamento deve ser considerado um caso particular do possível, e não o único modelo dessa relação.

Além disso, o autor aborda crescentemente, em suas obras, aqueles casos em que as disposições subjetivas se encontram mal ajustadas às possibilidades objetivas, devido ao que ele chama de "efeito de histerese", quando as condições de produção dos esquemas do habitus não são as mesmas de seu funcionamento. Na Distinção, ele explora os casos do chamado "novo rico", que tendo conquistado uma ascensão social, aplica esquemas de percepção, de pensamento e de ação que remetem às suas experiências passadas, sem êxito na apropriação do estilo de vida da classe dominante. Do mesmo modo, tratando das classes populares, Bourdieu (2013b, p. 351) afirma que o efeito do "gosto de necessidade" nunca é tão visível quanto no caso em que, agindo de alguma forma a 
contratempo, ele sobrevive ao desaparecimento das condições de que é o produto. Contudo, Martucelli (2007) destaca que os casos em que é possível observar o efeito de histerese na teoria de Bourdieu são considerados como anomalias e não integram seu esquema teórico. Para ele, Bourdieu enfatizaria a unicidade e sistematicidade do habitus, negligenciando seus desajustes e as possíveis crises.

No enfoque teórico de Bourdieu, o habitus tende a garantir sua própria constância e sua própria defesa contra a mudança, devido ao peso particular das experiências primitivas. Desse modo, ele opera uma seleção entre as informações novas e rejeita, em caso de exposição fortuita ou forçada, aquelas capazes de questionar a informação acumulada. Segundo Bourdieu (2013a, 2013b) basta pensar na homogamia como o paradigma de todas as "escolhas" do habitus (entre lugares, amigos, casamento etc.), que tendem a favorecer as experiências destinadas a reforçá-lo. Assim, o habitus tende a se proteger das crises e dos questionamentos críticos, garantindo-se um meio ao qual está pré-adaptado, ou seja, um universo de situações que reforçam suas disposições. Mas isso não significa que o autor não considere os desajustes entre o sistema de disposições subjetivas e as condições objetivas nas situações mais comuns da vida cotidiana dos indivíduos.

Ademais, de acordo com sua sociologia reflexiva, o conceito deve ser trabalhado à luz das propriedades específicas do objeto empírico a ser analisado, ou seja, segundo as condições objetivas de constituição do objeto, de modo que as construções conceituais não estão dadas de maneira definitiva, acima das preocupações empíricas do sociólogo. Portanto, o caráter unitário e durável do habitus, ou, por outro lado, suas tensões e a pluralidade das disposições, depende das condições sociais e históricas de constituição do objeto que se quer analisar.

Outra crítica direcionada ao enfoque praxiológico de Bourdieu corresponde à sua ênfase no caráter tácito ou "pré-reflexivo" da operação do 
habitus, o que o conduziria a uma negligência com relação à capacidade reflexiva e discursiva do agente. Essa ênfase é percebida como uma das fontes do neo-objetivismo de Bourdieu, que não teria conseguido superar a oposição entre objetivismo e subjetivismo ao propor uma teoria sintética da relação agência/estrutura ${ }^{4}$ (Peters, 2013, p. 48).

É importante destacar que Bourdieu estava preocupado em se contrapor ao pensamento econômico, que pensa os agentes a partir da perspectiva do "ator racional" ou de um modelo mecânico, em que esses seriam regulados por estruturas externas, como o mercado. Neste esforço de forjar uma alternativa para pensar a lógica da prática, o autor coloca uma grande ênfase no seu caráter tácito e pré-reflexivo, afirmando que o senso prático é ao mesmo tempo uma teoria e sua negação como teoria. Para o autor, o aprendizado dos esquemas de percepção e ação - que são a condição de todo pensamento e de toda prática razoáveis - é sempre prático. Na medida em que tais esquemas são reforçados por ações e discursos produzidos segundo os mesmos esquemas, eles são excluídos do universo dos objetos de pensamento (Bourdieu, 2013a).

Assim, a lógica prática se inscreve diretamente na ginástica corporal, sem passar pela apreensão expressa dos aspectos retidos ou descartados, suscitando, muitas vezes, uma identidade de reação que imprime ao corpo a mesma postura em contextos diferentes. As disposições geradas pelo habitus só aparecem ao agente na relação com uma situação, na passagem ao ato, de modo que a prática exclui qualquer interesse formal. O retorno reflexivo à ação ocorre geralmente em caso de fracasso dos automatismos e permanece subordinado à busca do resultado e da maximização do rendimento do esforço gasto. Ele não busca explicar como o resultado foi alcançado nem compreender a lógica da prática.

\footnotetext{
${ }^{4}$ Segundo Peters (2013, p. 54), os processos de autorreflexão e autotransformação reflexiva só podem ocorrer nos quadros da teoria bourdieusiana em duas situações: a partir do efeito de histerese ou pelo trabalho de auto-objetivação possibilitado pela sociologia.
} 
Por isso, a reflexividade que os agentes podem alcançar, em casos de situações problemáticas, é diferente da reflexividade da ciência. Enquanto a ciência busca apreender os princípios da produção da lógica prática através de instrumentos de objetivação e por uma relação de distanciamento com o objeto, o senso prático se caracteriza por uma relação prática com a prática, sem reflexão consciente nem controle lógico. Segundo Bourdieu (Ibid., p. 152), a prática exclui o retorno sobre si mesma (isto é, sobre o passado), ignorando os princípios que a comandam e as possibilidades que ela encerra e que não pode descobrir senão agindo-as, desdobrando-a no tempo.

O enfoque teórico bourdieusiano termina por negligenciar as possibilidades dos agentes em lançar mão de capacidades reflexivas no decorrer de suas práticas nas mais diversas situações. Mas essa lacuna pode ser entendida como decorrência de um esforço contínuo, observado ao longo de suas obras, no sentido de destacar o papel dos esquemas de percepção e de ação na reprodução das estruturas objetivas, através das práticas. Para Bourdieu (Ibid., pp. 157-158), a coerência observada nos produtos da aplicação de um mesmo habitus não tem outro fundamento senão a coerência desses princípios geradores com as estruturas sociais das quais são o produto e que tendem a reproduzir, ao inseri-las na estrutura de um sistema de relações simbólicas.

Para o autor, a sociologia não se limita à análise da posição social a partir da qual os agentes produzem os discursos sobre o mundo social, mas ela constitui uma das armas mais eficazes da crítica científica e política do discurso científico e político, inclusive dos usos políticos da legitimidade "científica". Nas suas palavras,

forçando a descobrir a exterioridade no coração da interioridade, a banalidade na ilusão da raridade, o comum na busca do único, a sociologia não tem somente por efeito denunciar todas as imposturas do egotismo narcísico; ela 
oferece um meio, talvez o único, de contribuir, nem que seja pela consciência das determinações, à construção, que de outro modo poderia ser abandonada às forças do mundo, de algo como um sujeito (Bourdieu, Ibid., p. 40).

\section{Bernard Lahire: patrimônios individuais de disposições}

Assim como Bourdieu, Lahire está interessado em pensar a prática, superando as oposições entre a teoria do ator racional, do habitus, do ator em interação etc., a partir do confronto teórico e empírico com as tensões interpretativas envolvidas nessas oposições, a saber, entre: a) as teorias que privilegiam a unicidade do ator e aquelas que destacam sua fragmentação; b) as teorias da ação consciente e as teorias da ação infraconsciente; c) o peso determinante atribuído ao passado do ator ou a ênfase na situação. Para tanto, o autor privilegia um diálogo crítico com a teoria da prática formulada por Bourdieu, a partir da qual ele nutre sua própria posição sociológica acerca dos móveis da ação.

Para Lahire (2002, p. 11), Bourdieu desenvolveu uma das orientações teóricas mais estimulantes e complexas nas ciências sociais, integrando o máximo de sutilezas teóricas e metodológicas nas grandes correntes das sociologias críticas. Portanto, o autor convida a pensar com e contra seu mestre, adotando um espírito crítico e investigativo que o conduz a um programa de sociologia à escala individual, que forneceria as condições de um estudo sociológico cada vez mais singular do social. Segundo Coutinho e Pontes (2013, p. 3), esse programa corresponderia a uma radicalização da própria sociologia e à ambição de elevá-la à altura de suas promessas fundacionais.

Segundo Lahire (2013), a compreensão das práticas e dos comportamentos pressupõe uma concepção do social em estado incorporado, sob a forma de disposições para crer, agir e sentir. Desse modo, o autor 
propõe o estudo da realidade social na sua forma interiorizada, ou seja, um estudo que apreenda o social refratado num corpo individual, que atravessa instituições, grupos e campos de luta diferentes. Seu objetivo é desenvolver uma sociologia disposicional que ultrapasse a simples invocação do passado incorporado, reconstruindo a gênese das disposições, investigando a constituição social e as modalidades de atualização desse passado, bem como os modos de socialização que formam tais disposições. Um programa de sociologia à escala individual permitiria ir além da mera evocação das operações do habitus, tal como feito por Bourdieu, investigando seus mecanismos de inculcação.

Uma de suas principais críticas ao enfoque teórico de Bourdieu corresponde ao princípio da transferibilidade das disposições como algo generalizável a priori, pois, para ele, tal premissa deve ser estudada empiricamente. Lahire (2005, p. 25) afirma que a transferibilidade de uma disposição é muito relativa, sendo mais provável quando o contexto de mobilização está próximo, no seu conteúdo e na sua estrutura, do contexto inicial de aquisição. Desse modo, a teoria de Bourdieu reduziria o complexo processo de exteriorização da interioridade a um funcionamento único e simples de assimilação das situações aos esquemas incorporados e de acomodação dos esquemas adquiridos anteriormente às mudanças de situação.

Segundo o autor, as pesquisas empíricas orientadas por uma sociologia à escala individual apontam a existência de esquemas de disposições de aplicação muito localizada, própria de situações sociais ou de domínios de prática particulares. Desse modo, elas permitem questionar se ao invés de um simples mecanismo de transferência, não há um mecanismo mais complexo de suspensão/ação ou de inibição/ativação de disposições, que supõem que cada indivíduo seja portador de uma pluralidade de disposições e atravesse uma pluralidade de contextos sociais. 
No entanto, é importante ressaltar que a própria crítica de Lahire tem sido questionada por autores que percebem no princípio da transferibilidade uma das maiores riquezas do enfoque praxiológico de Bourdieu, que garante a capacidade geral e inventiva do habitus, capaz de atuar em diferentes domínios da prática, por meio da transferência analógica baseada em situações semelhantes ocorridas anteriormente. É o caso de Jean-Claude Kaufmann (2003, p. 187), para quem a força do conceito de habitus estaria no seu caráter comutatório, multiforme e imperceptível 5 . Para esse autor, Lahire confunde o contexto da pesquisa, que deve revelar um aspecto do hábito, precisamente contextualizado, e os diversos laços deste hábito com universos múltiplos. Portanto, não seria possível encerrá-lo dentro de um universo todo ele observável, reduzindo suas relações ao que pode ser apreendido na pesquisa empírica.

O pano de fundo da crítica dirigida a Bourdieu corresponde ao crescente processo de individualização e diferenciação das sociedades modernas, sobretudo a partir dos anos 1960, em que os indivíduos são constantemente confrontados com processos multiformes de incorporação do social e se caracterizam por uma pluralidade interna de disposições heterogêneas, e até mesmo contraditórias. O autor ressalta, contudo, que seu enfoque teórico se distancia daqueles que afirmam que as classes sociais não existem mais ou que negligenciam toda espécie de objetos macrossociais - instituições, ambientes, grupos ou classes. Embora sua perspectiva teórica tenha sido associada a tais tendências, ele argumenta que é suficiente conferir a importância das classes sociais e dos grupos em seus sucessivos trabalhos, inclusive nos estudos de caso em que os indivíduos estudados são inseridos no espaço social e apreendidos no quadro das

\footnotetext{
${ }^{5}$ Assim como Lahire, Kaufmann parte de um diálogo crítico com a teoria da prática de Bourdieu, buscando integrar a dimensão individual na explicação da ação, muito embora este último trilhe um caminho teórico diferente do primeiro, cujas especificidades não poderão ser analisadas no âmbito deste trabalho.
} 
instituições familiares, escolares, dentre outras. Segundo Lahire (2013, pp. 22-23), o estudo do social em estado dobrado não teria sentido algum caso não pudesse se apoiar no estudo do social em estado desdobrado.

Desse modo, Lahire (Ibid., p. 23) afirma que a adoção de uma escala individual, que permite apreender as complexidades disposicionais de indivíduos socialmente situados, não significa que ele questione a existência de distâncias entre as classes sociais. Pelo contrário, ele parte das posições ocupadas no espaço social para complexificar o modelo de determinações. Nas suas palavras,

complexificar a rede de determinações que pesam sobre cada indivíduo singular em nada autoriza estilhaçar toda distinção entre propriedades principais e secundárias ou a tomar certas singularidades ou certas dimensões da condição de classe por princípios explicativos separáveis e independentes.

No entanto, quando a lógica de pesquisa conduz à análise do comportamento singular de um determinado indivíduo, mais do que do comportamento coletivo de alguns indivíduos considerados enquanto membros de um grupo ou classe, faz-se necessário investigar o conjunto da modelagem social pelo qual o indivíduo passou, começando pela família no interior da qual ele experienciou sua classe, explorando seu meio escolar, de trabalho, cultural, religioso etc ${ }^{6}$. Nessa perspectiva, os indivíduos são percebidos como diferentes variações da incorporação plural do espaço social. Considerando a pluralidade de disposições e de contextos sociais que atravessam os indivíduos, o autor afirma que não há um princípio único gerador de todas as práticas, que podem ser transferidos de um domínio a outro, como afirmara Bourdieu.

\footnotetext{
${ }^{6}$ De acordo com Lahire (2013), é desse gênero de sutilezas que a sociologia dos intelectuais necessita, em seu esforço de compreensão das obras, mas a sociologia à escala individual também pode ser aplicada em qualquer estudo que busque apreender as práticas e comportamentos de um indivíduo particular.
} 
Lahire (2005, p. 20) também questiona a definição do habitus como necessidade feita virtude como único modelo da relação com as disposições. Tal modelo pressupõe que a disposição seja forte, sem considerar que as disposições se distinguem entre elas segundo o seu grau de fixação e a sua força. O autor destaca que os atores não têm a mesma relação com seus múltiplos hábitos incorporados ${ }^{7}$. Estas relações dependem da maneira como tais disposições foram adquiridas, do momento da biografia individual em que foram incorporadas e do contexto atual de sua atualização. Somente nos casos em que os hábitos foram interiorizados precocemente, em condições favoráveis à sua boa interiorização e encontram condições positivas de concretização é que tal relação com a disposição pode ser denominada como paixão.

Segundo este autor, no modelo bourdieusiano, a adesão à prática é tão forte que qualquer dúvida é apagada. O ator não resiste nem é atraído por outras vontades e pulsões. Partindo da crítica da unicidade e sistematicidade do habitus, Lahire privilegia a análise daqueles casos em que, encarando um novo contexto de vida - casamento, divórcio etc. - os atores desejam se desvencilhar de alguns hábitos duravelmente instalados, que agora consideram maus hábitos. Suas hipóteses estão ligadas a uma concepção do indivíduo como produto complexo de diversos processos de socialização em contextos sociais múltiplos e heterogêneos. Segundo ele, o singular é necessariamente plural. (Lahire, 2005, p. 25)

\footnotetext{
${ }^{7} \mathrm{O}$ autor faz uma distinção entre os termos "disposição" e "apetência" para distinguir as diferentes situações. Assim, as disposições podem tomar a forma individual de uma paixão (disposição + forte apetência), de uma rotina (disposição + falta de apetência ou indiferença) ou de um mau hábito (disposição + rejeição e resistência com relação a essa disposição). Assim, por exemplo, naqueles casos em que a criança cresceu em um ambiente familiar estimulante, ela pode desenvolver uma "paixão" pelos estudos durante a sua vida escolar, mas pode não apresentar o mesmo interesse nas aulas de educação física, o que pode se constituir apenas numa falta de apetência (indiferença) ou ainda em uma resistência à prática de esportes (mau hábito).
} 
Em seu enfoque, o autor faz uma distinção entre as disposições para crer e as disposições para agir. As primeiras são as crenças incorporadas pelos indivíduos, mas que não podem ser sistematicamente assimiladas a disposições para agir. Tais crenças estão ligadas a normas sociais produzidas e difundidas por diferentes instituições, sendo incorporadas independentemente dos hábitos de ação incorporados paralelamente. Sua força varia em função do seu grau de constituição (aprendizagem) e de confirmação (sobreaprendizagem).

Para Lahire (2002, 2005), a consideração teórica das distâncias entre o que os atores dizem que fazem e o que pode ser apreendido através da observação dos seus comportamentos possibilita apreender os casos em que os atores interiorizam normas, valores e ideais sem terem forjado hábitos de ação que lhes permitam atingir o seu ideal, ou ainda aqueles casos em que, tendo incorporado crenças, eles não têm os meios materiais para concretizá-las. É o caso, por exemplo, dos atores que vivem num ambiente ideológico-cultural que valoriza os benefícios do consumo e sonham em aceder ao mesmo para "se sentir bem" e "ser feliz". Mas esses mesmos atores podem estar privados dos meios econômicos para agir no sentido de sua crença e vivenciar essas situações como uma frustração temporária ou permanente.

É o desajuste entre crenças e condições objetivas de existência que conduz, muitas vezes, a sentimentos de frustração, de culpabilidade ou de ilegitimidade. Portanto, é importante distinguir os diferentes elementos constitutivos da estrutura complexa que formam as combinações individuais de disposições para agir e de crenças. Neste modelo teórico, os atores são concebidos como colagens compostas, complexos matizados de disposições (para agir e para crer) mais ou menos fortemente constituídos (Lahire, 2005, p. 32).

O autor ressalta que sua concepção do ator plural também se distancia dos enfoques teóricos contemporâneos que enfatizam uma fragmentação infinita do indivíduo, como a perspectiva de Kaufmann. Sem 
contestar a legitimidade da diferenciação mais sutil da realidade social, Lahire (2002, p. 22) considera que tal fragmentação torna difícil a estruturação dos objetivos da pesquisa. Ademais, nessas abordagens há sempre o risco inverso de cair numa espécie de empirismo radical que captaria apenas uma pulverização de identidades, de comportamentos e papéis, sem nenhuma ligação entre eles ${ }^{8}$.

Do mesmo modo, seu enfoque se diferencia tanto do individualismo metodológico - que concebe um indivíduo dessocializado - quanto das interpretações pós-modernas - que tomam a fragmentação do ator como pressuposto a priori e não como hipótese a ser testada através de trabalhos empíricos. Para o autor, a questão da unicidade ou da pluralidade do ator é tanto uma questão histórica (e empírica) quanto uma questão teórica, que deve apreender as condições socio-históricas que tornam possível a produção do ator plural ou de um ator caracterizado por uma profunda unicidade. Quanto mais o indivíduo estiver colocado no seio de uma pluralidade de contextos sociais não homogêneos, ou mesmo contraditórios, mais essa experiência é vivida de maneira precoce e mais esse indivíduo se constituirá de um patrimônio de disposições, de hábitos e de capacidades não homogêneos, variando segundo o contexto social no qual tenha se desenvolvido. O problema da natureza e da organização do patrimônio individual coloca-se, portanto, no trabalho empírico.

$\mathrm{Na}$ tentativa de demarcar a especificidade de seu próprio enfoque teórico, Lahire (2002, p. 51) afirma que, enquanto Bourdieu atribui maior

\footnotetext{
${ }^{8}$ É importante destacar, contudo, que o próprio Kaufmann discorda da afirmação de Lahire acerca de uma fragmentação infinita do indivíduo em sua teoria. Segundo ele, há uma variedade de registros da pluralidade, de modo que ele e Lahire não se referem à mesma coisa. Enquanto este último se refere aos casos de clivagem do eu e à pluralidade dos contextos de ação, Kaufmman (2003, p. 182) ressalta também a multiplicidade de esquemas de ação interiorizados e incorporados. Mas, se por um lado, o indivíduo interioriza uma pluralidade de esquemas, por outro lado, quanto mais se reduz aos esquemas verdadeiramente incorporados, operatórios e ativos, mais se definem linhas de coerência. Portanto, o fracionamento infinito de esquemas não significa que a identidade se divida.
} 
peso explicativo ao passado incorporado, ele confere precedência teórica à situação presente na explicação da ação, sobretudo se os atores são considerados plurais. Segundo ele, em condições homogêneas de socialização, as reações do indivíduo às situações novas podem ser previsíveis, mas quando esses atores são o produto de formas de vida heterogêneas, a situação presente se torna central na reativação de uma parte das experiências passadas incorporadas. Contudo, é possível observar, sobretudo em seus trabalhos de cunho mais empírico, como Retratos Sociológicos, que o autor considera no mínimo em igual medida o peso do passado e dos processos de socialização secundária, possibilitando análises inovadoras acerca do processo de constituição e de atualização de disposições no interior das trajetórias individuais.

A mudança de escala da sociologia também permitiria apreender as variações interindividuais e intraindividuais das práticas, construindo uma visão do mundo social que não negligencia as singularidades individuais e evita a caricatura cultural dos grupos e classes sociais. Lahire (2002, 2005) propõe uma análise das variações interindividuais e intraindividuais em função dos diferentes contextos - domínios da prática, tipos de interação etc. Em suas pesquisas, o autor parte de uma análise dos próprios indivíduos, observando que eles podem fazer parte de públicos diversificados e até mesmo heterogêneos para constatar que não há uma fronteira definitiva entre legitimidade cultural e ilegitimidade cultural, separando as classes dominantes das classes dominadas. Os indivíduos, de qualquer classe social, transitam entre práticas e consumos da cultura legítima e da "baixa cultura" entre os diferentes domínios 9 .

\footnotetext{
${ }^{9} \mathrm{O}$ autor destaca, no entanto, que embora a frequência estatística dos perfis culturais individuais compostos por elementos heterogêneos ou dissonantes seja relativamente grande em todos os grupos sociais, ela é mais comum nas classes médias e superiores, nos níveis de escolaridade mais elevados e nos grupos etários mais jovens (Lahire, 2005, p. 30).
} 
O autor também critica a ênfase de Bourdieu no caráter pré-reflexivo do habitus, afirmando que os casos em que os atores lançam mão de capacidades reflexivas na realização de suas atividades são mais comuns do que o autor do Senso prático previu. Na sua análise das práticas escolares, Lahire (2002, p. 104) observa que a escola é, entre todos os universos socializadores, aquele que opera de maneira mais sistemática e duradoura uma ruptura com o senso prático linguístico. Ela possibilita uma relação reflexiva e distanciada com a linguagem, tratando-a como objeto a ser dissecado, analisado e manipulado; descobrindo as regras de sua estruturação interna.

Lahire (2002, p. 111) argumenta que os atores não possuem apenas uma relação pragmática com a linguagem, mas podem se servir da língua como um sistema de formas normalizadas, sobretudo quando são escolarizados. A relação reflexiva e distanciada com a linguagem é construída pela escola através de inúmeros exercícios escolares, de instrumentos de objetivação da linguagem, que chamam a atenção do aluno para as propriedades específicas do sistema de signos linguísticos.

O autor destaca as condições sociais e intelectuais que possibilitam tal relação, questionando a tese bourdieusiana segundo a qual essa relação seria possível a partir de uma suspensão das urgências temporais e de um distanciamento das necessidades práticas. Ele afirma que, embora o modelo teórico de Bourdieu não seja contestável em si, uma vez que descreve bem uma parte do mundo social visto sob seu ângulo econômico, ele é abstrato e impreciso, ancorado numa economia da análise das práticas de linguagem ${ }^{10}$.

\footnotetext{
${ }^{10} \mathrm{O}$ autor explica que Bourdieu designa com as mesmas expressões (disposição distante, gratuita etc.) um exercício escolar realizado na escola elementar, uma pergunta de sondagem política e uma visão vanguardista no campo da literatura ou da pintura.
} 
A análise de práticas de escrita doméstica mostra que estas representam verdadeiras rupturas com a lógica prática, podendo ser compreendidas pela relação negativa que mantêm com a memória incorporada do habitus. A escrita parece intervir quando o senso prático não é suficiente. Para tanto, os atores utilizam instrumentos de objetivação do tempo (calendário, agenda), as listas de coisas a dizer ou a fazer (lista de compras, livro de contas), itinerários traçados, que introduzem uma distância entre o ator e a sua prática e dão os meios para o domínio simbólico do que se dominava praticamente até então (o tempo, o espaço, a linguagem).

Tais instrumentos constituem exceções cotidianas com relação ao ajustamento pré-reflexivo do senso prático às situações sociais. Eles possibilitam organizar e planejar uma prática fora dela, antes de sua efetuação e, ao mesmo tempo, desfazer a urgência da prática que pesa sobre a ação. $\mathrm{O}$ autor destaca tanto a possibilidade de uma volta reflexiva à ação, como também de sua preparação reflexiva. A reflexão e o ajustamento pré-reflexivo, o planejamento e a rotina não são incompatíveis e não cessam de encadear-se na vida cotidiana.

A incursão sociológica nas práticas de escrita abre, portanto, uma brecha na teoria do senso prático. Se Bourdieu considerou a importância das práticas escriturais e gráficas como instrumentos que permitem um distanciamento da prática, Lahire constatou que essas técnicas de objetivação não estavam reservadas apenas aos eruditos. Embora os eruditos as utilizem há mais tempo e com mais frequência do que os outros atores, esses também inculcaram tais técnicas, através da socialização escolar, e fazem uso delas diariamente.

Para Lahire, a teoria de Bourdieu encontra seu campo de pertinência no estudo de universos sociais com fraco grau de objetivação das chamadas sociedades sem escrita. Segundo ele, a teoria do habitus teria sido construída com base no modelo da sociedade camponesa argelina, tradicional fracamente diferenciada -, tendo sido utilizada, posteriormente, para pen- 
sar as sociedades com forte diferenciação. Tal manobra estaria na raiz de alguns equívocos que o autor identifica nessa teoria, como a confusão em torno do hábito como modalidade da ação (involuntária, não intencional) com o gênero de hábito, que pode ser de reflexividade ou não. Como o hábito de gênero pré-reflexivo não é o único possível, a teoria do habitus de Bourdieu reduz o hábito como modalidade da ação a um gênero particular de hábito, a saber, o gênero não reflexivo (Lahire, 2002 p. 143).

Para o autor de Homem Plural, os problemas na abordagem de Bourdieu decorrem, em boa medida, de sua tentativa de relacionar as questões relativas a uma teoria da prática com a questão das diferenças culturais entre os grupos e classes. Ao relacionar a constituição das disposições às condições materiais da existência, Bourdieu defende que a propensão ao domínio simbólico da prática está restrita àqueles grupos sociais que possuem um distanciamento com relação ao mundo e às suas necessidades econômicas, enquanto os membros de diferentes grupos sociais são mais ou menos movidos pelo senso prático. Contudo, nessa teorização, o conceito de habitus parece ora subsumir a oposição domínio prático/domínio simbólico, ora se restringir ao domínio prático, sem consciência e pré-reflexivo.

Nesse segundo caso, o habitus não poderia ser o princípio de engendramento de todas as práticas, e o próprio Bourdieu convida a refletir sobre os modos de existência diferentes dos princípios de regulação e de regularidade das práticas. Buscando evitar tais ambivalências, Lahire adota o conceito de hábito, entendendo que esse conceito admite variações sociais relevantes do ponto de vista da importância relativa dos hábitos de reflexividade nos programas de socialização dos diferentes atores sociais.

O autor também critica a teoria do senso prático por explorar apenas exemplos esportivos para ilustrar a relação prática com a prática. Embora o exemplo do esportista "no calor da ação" ilustre perfeitamente o domínio prático, a especificidade de sua lógica não pode ser estendida a 
todas as práticas. A urgência não é uma propriedade de todas as práticas; a ação não é sempre redutível ao gesto executado.

Com relação à questão da intencionalidade ou não intencionalidade da ação, é válido ressaltar que as diferenças observadas entre os enfoques teóricos de Bourdieu e Lahire parecem corresponder ao tipo de escala utilizada e à sequência da ação considerada na análise. Se Bourdieu enfatiza o aspecto não intencional da prática, enquanto intenções explícitas e conscientes, é porque as situações evocadas são pensadas ao nível das trajetórias e dos campos, com sua lógica de lutas e relações de força. Nessa perspectiva, os indivíduos não possuem uma consciência explícita de todos os recursos e motivações de que lançam mão no desdobramento de suas ações. Geralmente, os atores desenvolvem intenções e planos num domínio específico, por ocasião desta ou daquela prática, que podem ser apreendidas a partir da adoção de uma escala particular de construção dos contextos de ação - como busca fazer Lahire.

Mas apesar do seu esforço em combater o determinismo sociológico através de uma análise das práticas individuais que busca enfatizar os hábitos reflexivos, Lahire também é criticado por não abordar adequadamente a questão da reflexividade. Kaufmann (2003) afirma que o autor acaba diluindo os hábitos reflexivos no conjunto dos hábitos, de modo a dificultar a análise de suas especificidades, tais como seu funcionamento e sua relação com os hábitos pré-reflexivos.

Ademais, é possível observar que Lahire não consegue romper totalmente com a tendência objetivista das ciências sociais, na medida em que ele concebe a reflexividade como um produto dos diferentes programas de socialização pelos quais passam os atores sociais. Como afirma Vandenberghe (2013, p. 74), até mesmo as práticas mais individuais ou aquelas mais conscientes são entendidas por Lahire por referência a uma miríade de processos de socialização que encontram suas sedimentações 
corporais, mentais e emocionais em um estoque de disposições. Num certo sentido, sua sociologia à escala individual radicalizaria as promessas fundacionais da disciplina ao mostrar que o social atua até mesmo no núcleo mais íntimo da pessoa, rastreando os efeitos da socialização nos recantos mais profundos do indivíduo.

O autor destaca um sério déficit motivacional na teoria disposicional de Lahire, haja vista que as normas, valores e ideais que motivam as ações dos indivíduos são sempre explicadas em termos de disposições. As aspirações, planos ou projetos que fazem os indivíduos agir com vontade e consciência são explicados como manifestações de processos de socialização passados e seus motivos internos são reconduzidos a forças externas por ele interiorizadas. Embora Lahire admita a reflexividade, ele reativa o princípio da não consciência de Bourdieu para explicar as práticas dos atores em termos das determinações sociais, das quais os mesmos não têm consciência. Nas suas palavras, poderíamos dizer que somos demasiado multisocializados e multideterminados para adquirirmos plena consciência de nossos determinismos (Lahire, 2013, p. 25).

\section{Considerações finais}

A exposição feita aqui permite perceber que tanto Pierre Bourdieu quanto Bernard Lahire tentaram superar as dicotomias encontradas nas ciências sociais através da formulação de uma teoria disposicional da ação, que busca apreender a relação entre as condições sociais objetivas e as disposições subjetivas. Contudo, no embate travado com as teorias da ação intelectualistas, que enfatizam a racionalidade, a consciência e a intencionalidade, Bourdieu cai na ênfase oposta, do caráter pré-reflexivo e infraconsciente do senso prático, sublinhando o peso das condições objetivas na constituição das disposições subjetivas. $\mathrm{O}$ autor atribui a coerência e 
sistematicidade do conjunto das práticas de um agente, ou de um grupo de agentes, ao habitus, enquanto princípio gerador de todas as práticas.

É esse caráter homogêneo do habitus que Lahire critica, enfatizando a incorporação de disposições heterogêneas e até mesmo contraditórias pelos indivíduos, decorrente dos múltiplos processos de socialização nos diferentes contextos sociais. Em seu enfoque teórico, Lahire busca se distanciar da concepção de Bourdieu ao enfatizar a pluralidade interna do ator, seus conflitos internos e os desajustes entre as condições objetivas e as disposições. Para superar as lacunas da teoria bourdieusiana, Lahire adota a noção de hábito e de patrimônios individuais de disposições.

A despeito das diferenças importantes na noção de prática trabaIhada pelos autores - tais como a ênfase na unidade ou heterogeneidade das disposições, sua transmutabilidade geral ou limitada e seu caráter de classe ou suas variações individuais -, é válido destacar o status epistemológico da teoria e sua relação necessária com a pesquisa empírica, que aproxima as duas perspectivas teóricas. Desse modo, Peters (2010, pp. 33) ressalta o caráter disposicional dos construtos teóricos de Bourdieu, que está na base de sua defesa do uso de "conceitos abertos", dotados de certa flexibilidade definicional, de modo a possibilitar sua utilização criativa em uma gama de contextos socioempíricos distintos. Essa orientação se reflete no conjunto da obra de Bourdieu, em que o autor constrói a noção de habitus de acordo com suas preocupações empíricas, considerando as condições de constituição do objeto a ser analisado, bem como suas propriedades específicas. Assim, enquanto em obras como o Senso Prático seu enfoque teórico é mais facilmente interpretado como enfatizando um ajuste perfeito e a homogeneidade dos esquemas de ação, é possível perceber, sobretudo em seus trabalhos de cunho mais empírico, a riqueza do conceito de habitus, seu potencial de transmutabilidade na comutação percepção-ação e a presença de desajustes entre as disposições incorporadas no passado e a situação presente. 
Do mesmo modo, Lahire defende que as questões acerca da unicidade ou pluralidade do ator não devem ser tomadas a priori, mas como hipóteses a serem testadas através de trabalhos empíricos, considerando as condições sócio-históricas que tornam possível a sua produção. Há o entendimento, portanto, de que o caráter unitário e durável do habitus ou, por outro lado, suas tensões e a pluralidade das disposições não estão dadas de maneira definitiva na teoria. Sua construção depende das condições sociais e históricas de constituição do objeto que se quer analisar. Nessa perspectiva, a questão da intencionalidade do ator também deve ser considerada de acordo com a sequência da ação analisada, não podendo ser integrada no enfoque teórico de maneira definitiva.

Conforme discutido anteriormente, Lahire sugere uma "mudança de escala" que conduz ao social individualizado como forma de confrontar as diferenças observadas nos diferentes enfoques teóricos. No entanto, o autor não nega a relevância da análise das práticas sociais em termos de classes ou grupos sociais, apenas rejeita a transposição direta dessa análise para a escala individual. Além disso, ele acredita que a condução de pesquisas empíricas orientadas por uma sociologia à escala individual pode possibilitar a análise das diversas formas de incorporação do social, de sua transferibilidade, das variações intraindividuais e interindividuais e dos hábitos reflexivos.

Decerto, é inegável sua contribuição para pensar os mecanismos de inculcação das disposições subjetivas através dos diferentes processos de socialização, as possíveis descontinuidades entre disposições para crer e disposições para agir, as tensões entre disposições heterogêneas, de maneira que o autor fornece um arcabouço teórico fundamental para analisar a prática, sobretudo em contextos de mudança - sejam aquelas mudanças situadas no nível microssocial, como casamento ou divórcio, sejam aquelas mudanças num nível macro, como uma reestruturação das relações entre as classes sociais. 
Bourdieu, por sua vez, não ignora o crescente processo de diferenciação nas sociedades modernas; ele mesmo enfatiza as lutas simbólicas pela diferença específica entre os mais próximos, engendradas por uma sociedade competitiva. Mas, para ele, tal diferença mascara justamente as propriedades genéricas, o gênero comum, as solidariedades 'objetivas', a classe (Bourdieu, 2013a, p. 231). As lutas de competição que dividem os mais próximos são a antítese mais perfeita e a negação mais eficaz da luta contra outra classe, na qual se constitui a classe. Por isso, o autor destaca a importância teórica e política de construção de uma sociologia à escala dos grupos - para adotar uma linguagem cara a Lahire.

Embora Bourdieu reconheça que os indivíduos de uma mesma classe possuem uma trajetória singular que os diferencia, ele considera que a sociologia pode tratar como idênticos os indivíduos que são o produto das mesmas condições objetivas; cada sistema de disposição individual é considerado uma variante estrutural dos outros. Já para Lahire, é a tentativa de responder a questões de naturezas diversas, a partir de sua teoria da prática, o que conduz Bourdieu a uma concepção unilateral do habitus (como domínio prático) e da reflexividade (como reflexão teórica/erudita).

Mas a despeito de suas limitações na abordagem desses temas, o enfoque teórico-metodológico de Bourdieu é reconhecido justamente pelo seu caráter multidimensional, capaz de abranger as relações entre as condições de produção do habitus e os diferentes domínios da prática. Sua teoria possibilita pensar a prática na sua relação com as condições sociais de existência dos indivíduos e classes, destacando que os indivíduos não incorporam as mesmas disposições nem estabelecem a mesma relação com o mundo social. Portanto, a decisão sobre a utilização de um enfoque teórico à escala dos grupos ou à escala individual deve ser tomada à luz das preocupações empíricas do pesquisador, conforme a orientação desses autores. 
Bourdieu e Lahire também partilham de uma concepção semelhante de indivíduo como produto do social, constituído pela lógica específica através da qual incorpora as disposições subjetivas. Tal concepção é fundamental para compreender seus limites na superação das dicotomias que dividem as principais correntes sociológicas, posto que apesar das suas contribuições no desenvolvimento de uma sociologia da prática, os autores terminam por enfatizar o peso do social sobre as condutas individuais. Eles consideram a ação humana em termos da incorporação de disposições através dos diferentes processos de socialização, destacando o peso das condições objetivas na constituição dessas disposições e das condições de sua atualização no presente. Desse modo, tais dicotomias continuam a instigar os principais debates teóricos no campo sociológico e o tema da reflexividade tem sido tomado como um importante caminho na construção de uma teoria menos determinista que permita apreender o problema da agência humana.

Alguns teóricos da emergente "Sociologia do Indivíduo", como Jean-Claude Kaufmann (2003), conseguiram avançar nesse tema ao abordar as diversas situações em que os indivíduos se deparam com hábitos contraditórios e suas tentativas de transformação consciente e voluntária dos próprios hábitos. Segundo ele, na medida em que os papéis sociais já não definem as práticas com tanta força como no passado, é necessário que os atores se comportem de maneira mais reflexiva. Contudo, o autor considera o processo reflexivo como produto das contradições internas ao social e dos processos de socialização contraditórios. A reflexividade se manifestaria fazendo opções no conflito entre esquemas de ação. Portanto, sua abordagem permanece dentro daquela perspectiva que tende a explicar a conduta individual pelo social.

A teoria das conversações interiores de Margareth Archer também se destaca por enfatizar que os poderes causais da estrutura social preci- 
sam ser ativados pelos próprios atores para serem efetivos. Mas a autora tem sido criticada por atribuir uma ênfase excessiva na agência humana, negligenciando sua relação com o social. Vandenberghe (2013, p. 101) defende a importância de se desenvolver uma teoria disposicional e conversacional da ação, que considere a influência dos processos socializadores nas conversações interiores, quando os atores negociam com as circunstâncias e integram seus projetos num plano de vida realizável.

Adotando uma postura semelhante à de Bourdieu e de Lahire, pode ser frutífero desenvolver estudos sobre práticas sociais que dialoguem criticamente com esses enfoques teóricos, buscando superar suas lacunas e ambiguidades, questionando-os à luz de pesquisas empíricas, de modo a construir um arcabouço conceitual mais apropriado à apreensão da relação entre indivíduo e sociedade e, consequentemente, com maior capacidade de intervenção nas relações sociais.

Ana Rodrigues Cavalcanti Alves é doutoranda em Sociologia e Professora Temporária de Sociologia na Universidade Federal de Pernambuco.

$\triangle$ anarodrigues86@gmail.com

\section{Referências}

1. BOURDIEU, P. Espaço social e poder simbólico. In: Coisas Ditas. São Paulo, Editora Brasiliense, 1990.

2. BOURDIEU, P. O poder simbólico. Tradução de Fernando Tomaz. 16ed. Rio de Janeiro, Bertrand Brasil, 2012.

3. BOURDIEU, P. O senso prático. 3ed. Petrópolis, Rio de Janeiro, Vozes, $2013 a$. 4. BOURDIEU, P. A distinção - crítica social do julgamento. São Paulo, Editora Zouk/Edusp, 2013b.

5. COUTINHO, P; O. PONTES, T. P. Introdução. In: Homenagem a Bernard Lahire. Cadernos do Sociófilo. Quarto Caderno. Rio de Janeiro, IESP, UERJ, 2013. 
6. GARFINKEL, H. O que é etnometodologia? Tradução de Paulo Cortes Gago e Raul Francisco Magalhães. Juiz de Fora, 2009.

7. KAUFMANN, J-C. Ego, para uma sociologia do indivíduo. Tradução de Ana Rabaça. Instituto Piaget, 2003.

8. LAHIRE, B. O homem plural: os determinantes da ação. Petrópolis, Rio de Janeiro, Vozes, 2002.

9. LAHIRE, B. Patrimônios individuais de disposições. Para uma sociologia à escala individual. In: Sociologia, Problemas e Problemáticas. N. 49, 2005.

10. LAHIRE, B. Dans les plis singuliers du social: individus, institutions, socialisations. Paris: La Découverte, 2013.

11. MARTUCCELLI, D. Cambio de rumbo. La sociedad a escala del Individuo. Santiago, LOM Ediciones, 2007.

12. PETERS, G. Humano, demasiado mundano: a teoria do habitus em retrospecto. Teoria \& sociedade, v. 18, n. 1, 2010, p. 8-37.

13. PETERS, G. Habitus, reflexividade e neo-objetivismo na teoria da prática de Pierre Bourdieu. RBCS, v. 28, n. 83, 2013.

14. VANDENBERGHE, F. Teoria Social Realista: um diálogo franco-britânico. Belo Horizonte, Ed. UFMG; Rio de Janeiro, Ed. IUPERJ, 2010.

15. VANDENBERGHE, F. A sociologia na escala individual: Margaret Archer e Bernard Lahire. In: Cadernos do Sociófilo. Tradução de Gabriel Peters. Quarto Caderno. Rio de Janeiro, IESP, UERJ, 2013.

16. WACQUANT, L. Esclarecer o habitus. In: Educação e Linguagem. N. 16, 2007. Pp. 63-71.

Recebido em: 05/06/2015

Aceite final: 11/02/2016 